P83 (continued)

Target Audience: Low-income K-2 students and their families $(\mathrm{n}=32)$.

Theory, Prior Research, Rationale: The educational program is based on the social cognitive theory.

Description: "Cooking Club" was offered as an option for K-2 students as part of the after-school program at a Title I elementary school. A maximum of 12 students participate each quarter with 1 session each week for 5 weeks. Lessons were based on MyPlate, focusing on 1 of the food groups each week. Extension Educators introduced the food group using an educational activity, then help students prepare a simple recipe associated with the topic. The recipe and ingredients to make 4 servings was sent home with the student to prepare the recipe with their families.

Evaluation: A student pre- and post-test were administered before and at the end of each session to assess nutrition knowledge. Parent evaluations were sent home with each weekly recipe and an end-of-program survey assessed behavior change. Nutrition knowledge increase of K-2 students ranged from 14 to $36 \%$ for the 5 lessons. Parent feedback included: family enjoyed the recipe: 1.38 ; and more awareness of good nutrition 2.71 (5 point, Likert scale, $1=$ strongly agree; $5=$ strongly disagree); $93 \%$ stated they made the recipe and $62 \%$ stated they would make the recipe again.

Conclusions and Implications: Experiential activities during education programs increase knowledge/skills. Providing families with ingredients to make the recipe at home reinforced knowledge/skills gained from the educational sessions.

Funding: NIFA

Additional Funding: Project 2011-67001-30011

\section{P84 Discovery Neighborhood: A Youth Food Safety Educational Program}

Amanda Robine, BS, amr417@gmail.com, University of Nebraska-Lincoln, 2326 N. 60th Street, Lincoln, NE 68507; S. Wilson, BS; C. Larvick, MA; C. Schwarz, MS, RD; S. Purcell; P. Jones; C. Wells, MS, RD; M. Krehbiel, PhD; J. Albrecht, PhD, RD

Objective: To develop and conduct a youth food safety curriculum (K-5th grade).

Target Audience: K-5th grade youth

Theory, Prior Research, Rationale: Children are at a higher risk of contracting foodborne illnesses and these illnesses can be prevented with proper food handling techniques. A 6 lesson food safety curriculum was developed using the Conversation Map ${ }^{\mathrm{TM}}$ methodology and experiential learning activities.

Description: Discovery Neighborhood is a 6 lesson program designed for K-5 grade youth. The interactive program uses a Mat $\left(30^{\prime \prime} \mathrm{x} 36^{\prime \prime}\right)$ which illustrates a neighborhood. Each lesson focuses on one FightBac! ${ }^{\mathrm{TM}}$ food safety concept (handwashing, clean, separate, cook, chill and produce) with age-appropriate activities. Cartoon characters from the Discovery Neighborhood help youth learn the concepts of the curriculum. Each lesson has an optional food activity that reinforces the lesson's main concept. A family newsletter is distributed to the youth to share at home highlighting the main points of the lesson.

Evaluation: Each lesson contains a pre- and post- evaluation to measure knowledge learned. Discovery Neighborhood was piloted in 3 after-school settings in 3 different Nebraska communities. Participants $(n=33)$ completing the evaluations were mainly K-2 graders (75\%). An increase in knowledge was found for the handwashing (17\%), clean (12\% and positive identification of items to contaminate surfaces), separate (10\%) and cook (30\%) lessons.

Conclusions and Implications: Discovery Neighborhood is an educational program that provides youth (K-5) with food safety knowledge in an interactive and engaging way. The program is designed to use in an afterschool or in the school setting.

Funding: University of Nebraska-Lincoln Extension

\section{P85 Growing Healthy Kids: Parent Evaluation}

Johnna Hall, MS, RD, jhall21@unl.edu, University of Nebraska-Lincoln, 2326 N. 60th Street, Lincoln, NE 68507; A. Vierregger, MS, ACSM-HFS;

M. Anderson-Knott, MA; J. Albrecht, PhD, RD;

$W$. Koszewski, PhD, RD, University of North Dakota

Objective: Growing Healthy Kids is a School Enrichment Kit Program (K-2) developed to increase knowledge and improve nutrition/health behaviors.

Target Audience: K-2 students and their families Theory, Prior Research, Rationale: The School Enrichment Program is based on the Social Cognitive Theory which emphasizes a behavioral component with environmental and individual aspects.

Description: Growing Healthy Kids uses educational kits specifically developed for each grade (K-2) with ageappropriate curriculum and activities. Each kit contains 5 lessons which include: MyPlate, making healthy choices, how their bodies use food, meal planning, and physical activity. An extension educator delivers the kits and teaches an introductory lesson on hand washing. The kit is left with the teacher for three weeks to utilize. After three weeks, the extension educator returns to teach a final lesson, either healthy snacking or physical activity.

Evaluation: A postcard survey was sent to parents after students completed the program. A total of 637 surveys were returned following 2 years of program implementation. Among respondents, the majority reported improvement of health behaviors because of the program. More than half of respondents agreed that because of the School Enrichment Kit Program their families are more aware of the importance of good nutrition $(73.8 \%)$, are making healthier meal and/or snack choices (68.6\%), are more willing to try new foods $(60.6 \%)$, and are washing their hands more often before eating (58.2\%).

Continued on page $S 141$ 